\title{
TINGKAT KEBISINGAN DAN SUHU PADA USAHA STONE CRUSHER PT. X, KABUPATEN PASAMAN BARAT, PROVINSI SUMATERA BARAT
}

\author{
Yunasril $^{1}$, Heri Prabowo ${ }^{2}$ \\ Teknik Pertambangan Universitas Negeri Padang \\ email: inoes83@yahoo.co.id
}

\begin{abstract}
ABSTRAK
PT. X adalah salah satu perusahaan swasta yang bergerak disektor pertambangan, yaitu pengolahan pemurnian Stone crusher di Jorong Bandua Balai, Nagari Kinali, Kecamatan Kinali, Kabupaten Pasaman Barat Propinsi Sumatera Barat. Kegiatan pertambangan merupakan kegiatan yang padat akan aktivitas peralatan mesin yang dapat menimbulkan gangguan pada lingkungan kerja. Efek tekanan lingkungan kerja pada pekerja dapat berupa penurunan kualitas fisik dan nonfisik (psikologi) dan juga akan menjadi pemicu munculnya berbagai konflik lingkungan yang ada. Salah satu bentuk tekanan lingkungan adalah kebisingan dan suhu di tempat kerja. Pengukuran kebisingan di PT. X bertujuan untuk mengetahui apakah tingkat kebisingan di lokasi kegiatan Stone crusher memenuhi persyaratan menurut standar baku tingkat kebisingan berdasarkan Nilai Ambang Batas (NAB) yang telah ditetapkan oleh Keputusan Menteri Tenaga Kerja Nomor KEP-51/MENAKER/1999 untuk lokasi kerja. Dari hasil penelitian ini berdasarkan ruang lingkup kerja bahwa di lokasi penelitian pada jarak $3 \mathrm{~m}$ dari stone crusher untuk operatornya sebesar 97,31 dB, dan di daerah perlintasan pekerja pada jarak $6 \mathrm{~m}$ adalah sebesar 95,47 dB sementara di lokasi bengkel yang berjarak $12 \mathrm{~m}$ dari stone crusher sebesar 89,14 dB. Berdasarkan KEP51/MENAKER/1999 untuk semua lokasi pengukuran tersebut sudah melebihi Nilai Ambang Batas (NAB) yang diizinkan untuk pekerja yang terperjan kebisingan selama 8 jam/hari. Untuk hasil pengukuran suhu/tekanan panas lokasi operator dan lokasi bengkel rata-rata adalah $27,4^{0} \mathrm{C}$ dan $26,8^{0} \mathrm{C}$. Bila dirujuk kepada KEP-51/MENAKER/1999 untuk berkerja selama 6 jam/hari (75\% kerja) dengan status beban kerja sedang dengan Nilai Ambang Batasnya (NAB) $28^{0} \mathrm{C}$ berarti masih dibawah NAB. Tetapi bila bekerja penuh $8 \mathrm{jam} / \mathrm{hari}$ $(100 \%)$ kedua lokasi tersebut telah melebihi NAB yaitu $26,7^{\circ} \mathrm{C}$.
\end{abstract}

Kata kunci : Nilai Ambang Batas (NAB)

\section{PENDAHULUAN}

Kegiatan ekploitasi sumberdaya mineral atau bahan galian seperti batuan merupakan salah satu pendukung sektor pembangunan baik secara fisik, ekonomi maupun sosial. Hasil pertambangan merupakan sumberdaya yang mampu menghasilkan pendapatan yang sangat besar untuk suatu daerah. Kebutuhan akan bahan galian konstruksi dan industri seperti batuan tampak semakin meningkat seiring dengan semakin berkembangnya pembangunan berbagai sarana maupun prasarana fisik di berbagai daerah di Indonesia.

PT. X adalah salah satu perusahaan swasta yang bergerak disektor pertambangan, yaitu pengolahan pemurnian stone crusher di Jorong Bandua Balai, Nagari Kinali, Kecamatan Kinali, Kabupaten Pasaman Barat Provinsi Sumatera Barat. PT. X.

Kegiatan yang dilakukan
ahaan ini secara prinsip akan


mendukung kegiatan perekonomian disekitarnya dan meningkatkan Pendapatan Asli Daerah (PAD). Sama seperti kegiatan industri lainnya bahwa kegiatan mekanis dalam pertambangan dan perangkat permesinan pasti akan menghasilkan efek samping terhadap lingkungan sekitarnya. Salah satu aspek yang harus menjadi perhatian industri adalah kenyamanan bagi tenaga kerja saat melaksanakan pekerjaannya. Kenyamanan disini antara lain adalah kenyamanan audio dan kenyamanan suhu.

Kegiatan pertambangan merupakan kegiatan yang padat akan aktivitas peralatan mesin yang dapat menimbulkan suara yang mengganggu lingkungan, terutama lingkungan lokasi kegiatan pertambangan tersebut. Efek tekanan lingkungan pada manusia dapat berupa penurunan kualitas fisik dan nonfisik (psikologi). Salah satu bentuk tekanan lingkungan adalah kebisingan dan suhu/tekanan panas.

Berdasarkan observasi awal ditemukan bahwa tingkat kebisingan yang ditimbulkan oleh aktivitas stone crusher adalah melebihi ambang batas kebisingan yaitu $91 \mathrm{~dB}$ pada lokasi stone crusher dihitung selama 10 menit. Sesuai Keputusan Menteri Tenaga Kerja Nomor KEP-51/MENAKER/1999 tentang nilai ambang batas faktor fisik di tempat kerja, bahwa nilai ambang batas kebisingan di area kerja maksimal $85 \mathrm{~dB}$ dengan waktu pemajanan 8 jam. Disamping itu dilapangan ditemukan para pekerja tidak menggunakan APD (Alat Proteksi Diri) untuk peredam kebisingan seperti (ear plug/headphone), masker, safety shoes dan safety helmet dan lainnya.

Untuk suhu di lokasi stone crushera yang dimaksud adalah Indek Suhu Basak dan Bola (ISBB) yaitu sebesar $28,43^{\circ} \mathrm{C}$ dengan jenis pekerjaan di lokasi stone crusher termasuk jenis pekerjaan dengan beban kerja sedang. Dengan nilai demiakian berarti juga melebihi nilai ambang batas (NAB) yang telah ditentukan, yaitu $28,0^{\circ} \mathrm{C}$ berdasarkan KEP-51/MENAKER/1999.
Tujuan dari penelitian ini adalah:

1. Untuk mengetahui berapakah Tingkat Kebisingan di lokasi stone crusher selama jam kerja berlangsung dan apakah memenuhi syarat Nilai Ambang Batas (NAB) yang diperbolehkan berdasarkan KEP-51/MENAKER/1999

2. Untuk mengethui suhu di lokasi stone crusher selama jam kerja dan apakah memenuhi syarat Nilai Ambang Batas (NAB) yang diperbolehkan berdasarkan KEP51/MENAKER/1999

\section{METODOLOGI}

Penelitian ini menjelaskan tentang tingkat kebisingan dan suhu yang dirasakan oleh pekerja di lokasi stone crusher PT.X. Jenis penelitian ini adalah penelitian deskriptif. Pada penelitian ini nantinya akan memberikan hasil berupa tingkat kebisingan dan suhu di masingmasing lokasi pengamatan, kemudian dirujuk terhadap standar baku mutu menurut KEP-51/MENAKER/1999. Alat utama yang digunakan dalam penelitian ini adalah Sound Level Meter Type 2 Soundpro untuk tingkat kebisingan dan untuk suhu/tekanan panas menggunakan alat Thermal Environment Monitor.

Pengambilan data kebisingan di lokasi stone crusher diambil sebanyak 3 (tiga) lokasi dengan jarak 3 m, 6 m, dan 12 $\mathrm{m}$. Masing-masingnya diambil pada pukul 09.00 WIB untuk pagi hari, pada pukul 11.00 WIB untuk siang, dan pada pukul 15.00 WIB untuk sorenya. Penentuan jarak berdasarkan dengan ruang lingkup pekerja atau lokasi-lokasi kegiatan pekerja disekitar stone crsuher, seperti lokasi operator, perlintasan pekerja dan di bengkel.

Pengukuran suhu dilakukan di dua lokasi yaitu di lokasi operator dan bengkel. Lokasi ini di ambil karena pada lokasi inilah pekerja relatif menetap. Pengambilan data dilakukan pada pukul 09.00 WIB dan pada pukul 15.00 WIB. 
Kemudian hasil pengukuran suhu yang diperoleh di rujuk kepada KEP51/MENAKER/1999 tentang nilai ambang batas iklim kerja indeks suhu basah dan bola (ISBB).

\section{HASIL DAN PEMBAHASAN}

\subsection{Tingkat Kebisingan Leq 10 Menit}

Penelitian ini menentukan tingkat kebisingan lingkungan di lokasi kerja, dengan menggunakan alat Sound Level Meter Type 2 Soundpro SE/DL. Pengambilan sampel dilakukan di area Stone crusher pada jarak $3 \mathrm{~m}, 6 \mathrm{~m}$, dan $12 \mathrm{~m}$. Jarak ini diambil berdasarkan kepada ruang lingkup kerja. Pencatat data tingkat kebisingan dilakukan masing-masingnya selama 10 menit untuk pagi jam 09.00, siang jam 11.00 dan sore jam 15.00. Dengan ketinggian mikrofon adalah $1,5 \mathrm{~m}$ dari permukaan tanah untuk yang beraktifitas di tanah dan pada ketinggian $4 \mathrm{~m}$ untuk operator Stone crusher.

\subsection{Lokasi di Operator Stone Crusher}

Tabel 1. Tingkat Kebisingan di Lokasi Operator Pagi hari Jam 09.00 WIB Pada Jarak $3 \mathrm{~m}$

\begin{tabular}{|c|c|c|}
\hline No. & $\begin{array}{c}\text { Sound } \\
\text { Presure } \\
\text { Level (SPL) }\end{array}$ & $\begin{array}{c}\text { Tingkat } \\
\text { Kebisingan } \\
\text { (dBA) }\end{array}$ \\
\hline 1. & $\mathrm{SPL}_{\max }$ & 110,6 \\
\hline 2. & $\mathrm{SPL}_{\mathrm{eq}}\left(\mathrm{L}_{1}\right)$ & $\mathbf{9 8 , 3}$ \\
\hline 3. & $\mathrm{SPL}_{\min }$ & 81,6 \\
\hline
\end{tabular}

Tabel 2.Tingkat Kebisingan di Lokasi Operator Siang Hari Jam 11.00 WIB Pada Jarak $3 \mathrm{~m}$

\begin{tabular}{|l|c|c|}
\hline No. & $\begin{array}{c}\text { Sound } \\
\text { Presure } \\
\text { Level (SPL) }\end{array}$ & $\begin{array}{c}\text { Tingkat } \\
\text { Kebisingan } \\
\text { (dBA) }\end{array}$ \\
\hline 1. & SPL $_{\max }$ & 109,9 \\
\hline 2. & $\mathrm{SPL}_{\mathrm{eq}}\left(\mathrm{L}_{2}\right)$ & $\mathbf{9 5 , 6}$ \\
\hline 3. & $\mathrm{SPL}_{\min }$ & 78,9 \\
\hline
\end{tabular}

Tabel 3. Tingkat Kebisingan di Lokasi Operator Sore Hari Jam 15.00 WIB Pada Jarak $3 \mathrm{~m}$

\begin{tabular}{|l|c|c|}
\hline No. & $\begin{array}{c}\text { Sound } \\
\text { Presure } \\
\text { Level (SPL) }\end{array}$ & $\begin{array}{c}\text { Tingkat } \\
\text { Kebisingan } \\
\text { (dBA) }\end{array}$ \\
\hline 1. & SPL $_{\max }$ & 107,3 \\
\hline 2. & $\mathrm{SPL}_{\mathrm{eq}}\left(\mathrm{L}_{3}\right)$ & $\mathbf{9 7 , 6}$ \\
\hline 3. & $\mathrm{SPL}_{\min }$ & 80,8 \\
\hline
\end{tabular}

Sehingga SPLeq selama 8 jam untuk di lokasi Operator adalah :

$$
\begin{aligned}
& \mathrm{SPL}_{\text {eq }}=10 \log \left\{\frac { 1 } { 3 } \left(10^{0.1 L 1}+10^{0.1 L 2}+\right.\right. \\
& \left.\left.10^{0.1 L 3}\right)\right\} \\
& \mathrm{SPL}_{\mathrm{eq}}=10 \log \left\{\frac { 1 } { 3 } \left(10^{0.1(98.3)}+\right.\right. \\
& \left.10^{0.1(95.6)}+10^{0.1(97.6)}\right\} \\
& \mathbf{S P L}_{\mathbf{e q}}=\mathbf{9 7 . 3 1} \mathbf{d B}
\end{aligned}
$$

\subsection{Lokasi di Perlintasan Kerja}

Tabel 4. Tingkat Kebisingan di Lokasi Perlintasan Pagi hari Jam 09.00 WIB Pada Jarak $6 \mathrm{~m}$

\begin{tabular}{|l|c|c|}
\hline No. & $\begin{array}{c}\text { Sound } \\
\text { Presure } \\
\text { Level (SPL) }\end{array}$ & $\begin{array}{c}\text { Tingkat } \\
\text { Kebisingan } \\
\text { (dBA) }\end{array}$ \\
\hline 1. & SPL $_{\max }$ & 105,6 \\
\hline 2. & SPL $_{\mathrm{eq}}\left(\mathrm{L}_{1}\right)$ & $\mathbf{9 5 , 3}$ \\
\hline 3. & $\mathrm{SPL}_{\min }$ & 78,5 \\
\hline
\end{tabular}

Tabel 5. Tingkat Kebisingan di Lokasi Operator Siang Hari Jam 11.00 WIB Pada Jarak $6 \mathrm{~m}$

\begin{tabular}{|l|c|c|}
\hline No. & $\begin{array}{c}\text { Sound } \\
\text { Presure } \\
\text { Level (SPL) }\end{array}$ & $\begin{array}{c}\text { Tingkat } \\
\text { Kebisingan } \\
(\mathbf{d B A})\end{array}$ \\
\hline 1. & $\mathrm{SPL}_{\max }$ & 109,9 \\
\hline 2. & $\mathrm{SPL}_{\mathrm{eq}}\left(\mathrm{L}_{1}\right)$ & $\mathbf{9 5 , 6}$ \\
\hline 3. & $\mathrm{SPL}_{\min }$ & 78,9 \\
\hline
\end{tabular}


Tabel 6. Tingkat Kebisingan di Lokasi Perlintasan Sore hari Jam 15.00 WIB Pada Jarak 6 m

\begin{tabular}{|c|c|c|}
\hline No. & $\begin{array}{c}\text { Sound } \\
\text { Presure } \\
\text { Level (SPL) }\end{array}$ & $\begin{array}{c}\text { Tingkat } \\
\text { Kebisingan } \\
\text { (dBA) }\end{array}$ \\
\hline 1. & SPL $_{\max }$ & 105,0 \\
\hline 2. & SPL $_{\mathrm{eq}}\left(\mathrm{L}_{1}\right)$ & $\mathbf{9 5 , 9}$ \\
\hline 3. & $\mathrm{SPL}_{\min }$ & 79,1 \\
\hline
\end{tabular}

Sehingga SPLeq selama 8 jam untuk di lokasi Perlintasan adalah :

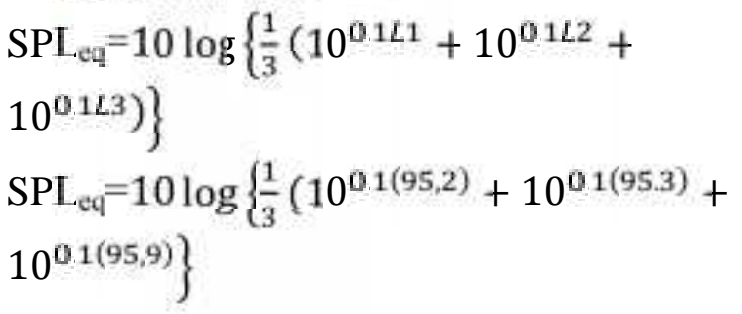

$\mathrm{SPL}_{\mathrm{eq}}=95.47 \mathrm{~dB}$

\subsection{Lokasi di Perlintasan Kerja}

Tabel 7.Tingkat Kebisingan di Lokasi Bengkel Pagi hari Jam 09.00 WIB Pada Jarak $12 \mathrm{~m}$

\begin{tabular}{|l|c|c|}
\hline No. & $\begin{array}{c}\text { Sound } \\
\text { Presure } \\
\text { Level (SPL) }\end{array}$ & $\begin{array}{c}\text { Tingkat } \\
\text { Kebisingan } \\
\text { (dBA) }\end{array}$ \\
\hline 1. & SPL $_{\max }$ & 97,2 \\
\hline 2. & SPL $_{\mathrm{eq}}\left(\mathrm{L}_{1}\right)$ & $\mathbf{8 9 , 6}$ \\
\hline 3. & $\mathrm{SPL}_{\min }$ & 72,8 \\
\hline
\end{tabular}

Tabel 8.Tingkat Kebisingan di Lokasi Bengkel Siang Hari Jam 11.00 WIB Pada Jarak $12 \mathrm{~m}$

\begin{tabular}{|c|c|c|}
\hline No. & $\begin{array}{c}\text { Sound } \\
\text { Presure } \\
\text { Level (SPL) }\end{array}$ & $\begin{array}{c}\text { Tingkat } \\
\text { Kebisingan } \\
\text { (dBA) }\end{array}$ \\
\hline 1. & SPL $_{\max }$ & 94,8 \\
\hline 2. & SPL $_{\mathrm{eq}}\left(\mathrm{L}_{1}\right)$ & $\mathbf{8 7 , 4}$ \\
\hline 3. & $\mathrm{SPL}_{\min }$ & 70,6 \\
\hline
\end{tabular}

Tabel 9. Tingkat Kebisingan di Lokasi Bengkel Sore Hari Jam 15.00 WIB Pada Jarak $12 \mathrm{~m}$

\begin{tabular}{|c|c|c|}
\hline No. & $\begin{array}{c}\text { Sound } \\
\text { Presure } \\
\text { Level (SPL) }\end{array}$ & $\begin{array}{c}\text { Tingkat } \\
\text { Kebisingan } \\
\text { (dBA) }\end{array}$ \\
\hline 1. & SPL $_{\max }$ & 99,7 \\
\hline 2. & SPL $_{\mathrm{eq}}\left(\mathrm{L}_{1}\right)$ & $\mathbf{8 0 , 0}$ \\
\hline 3. & SPL $_{\min }$ & 73,3 \\
\hline
\end{tabular}

Sehingga SPL $_{\text {eq }}$ selama 8 jam untuk di lokasi Bengkel adalah :

$$
\begin{aligned}
\mathrm{SPL}_{\mathrm{eq}}=10 \log \left\{\frac { 1 } { 3 } \left(10^{0.1 L 1}+\right.\right. \\
\left.\left.10^{0.1 L 2}+10^{0.1 L 3}\right)\right\}
\end{aligned}
$$

$\mathrm{SPL}_{\mathrm{eq}}=10 \log \left\{\frac{1}{3}\left(10^{0.1(89,6)}+\right.\right.$

$$
\left.\begin{array}{l}
10^{0.1(87,4)}+10^{0.1(90.0)} \\
\text { SPL }_{\mathbf{e q}}=\mathbf{8 9}, \mathbf{1 4} \mathbf{~ d B}
\end{array}\right\}
$$

Sehingga diperoleh Tingkat Kebisingan di Lokasi Stone Crusher adalah seperti pada Tabel 10 berikut ini :

Tabel 10. Tingkat Kebisingan di Lokasi Stone Crusher

\begin{tabular}{|l|c|c|c|}
\hline No. & Lokasi & Jarak & SPL $_{\text {eq }}$ \\
\hline 1. & Operator & $3 \mathrm{~m}$ & $\mathbf{9 7 , 3 1} \mathbf{~ d B}$ \\
\hline 2. & Perlintasan & $6 \mathrm{~m}$ & $\mathbf{9 5 , 4 7} \mathbf{~ d B}$ \\
\hline 3. & Bengkel & $12 \mathrm{~m}$ & $\mathbf{8 9 , 1 4} \mathbf{d B}$ \\
\hline
\end{tabular}

Dari hasil pengukuran dan perhitungan Tingkat Kebiisingan di Lokasi kegiatan Stone Crusher semuanya sudah melebihi Nilai Ambang Batas (NAB) menurut KEP51/MENAKER/1999 yaitu sebesar 85 dB untuk bekerja 8 jam /hari. Berdasarkan kenyataan ini maka sudah perlu ditekankan agar setiap pekerja di lokasi Stone Crusher ini memakai APD antara lain seperti ear muff atau ear plug atau yang lainnya.

\subsection{Pengukuran Suhu}

Pengukuran suhu dilakukan di dua lokasi yaitu lokasi operator stone crusher dan bengkel. Pengukuran suhu menggunakan alat Thermal Environmet Monitor, data diambil pada pukul 09.00 
WIB untuk pagi hari dan pukul $15.00 \mathrm{WIB}$ untuk sore hari. Data hasil pengukuran suhu tersebut adalah seperti tabel 5 berikut ini:

Tabel 11. Hasil Pengukuran dan Perhitungan Data Suhu Pagi Hari Jam 09.00 WIB

\begin{tabular}{|c|c|c|c|c|}
\hline \multirow{2}{*}{ Lokasi } & \multicolumn{3}{|c|}{ Hasil $\left({ }^{\circ} \mathbf{C}\right)$} & \multirow{2}{*}{ ISBB } \\
\cline { 2 - 5 } & $\begin{array}{l}\text { Dry } \\
\text { Bulb }\end{array}$ & $\begin{array}{l}\text { Wet } \\
\text { Bulb }\end{array}$ & Globe & \\
\hline Operator & 27,4 & 26,6 & 29,7 & 27,16 \\
\hline Bengkel & 27,1 & 25,7 & 29,2 & 26,54 \\
\hline
\end{tabular}

Perhitungan Suhu untuk pagi:

$\mathrm{ISBB}=0,7 \cdot 26,4+0,2 \cdot 29,7+0,1 \cdot 27,4$

(operator stone crusher)

$\mathrm{ISBB}=0,7.25,7+0,2.29,2+0,1 \cdot 27,1$ (bengkel)

Tabel 12. Hasil Pengukuran dan Perhitungan Data Suhu Sore Hari Jam 15.00 WIB

\begin{tabular}{|c|c|c|c|c|}
\hline \multirow{2}{*}{ Lokasi } & \multicolumn{3}{|c|}{ Hasil $\left({ }^{\circ} \mathbf{C}\right)$} & \multirow{2}{*}{ ISBB } \\
\cline { 2 - 5 } & $\begin{array}{c}\text { Dry } \\
\text { Bulb }\end{array}$ & $\begin{array}{c}\text { Wet } \\
\text { Bulb }\end{array}$ & Globe & \\
\hline Operator & 28,9 & 26,4 & 31,4 & 27,65 \\
\hline Bengkel & 28,7 & 26,2 & 29,2 & 27,05 \\
\hline
\end{tabular}

Dari hasil perhitungan suhu jika merujuk ke KEP-51/MENAKER/1999 untuk beban kerja sedang pada lokasi operasi dan bengkel masih di bawah Nilai Ambang Batas (NAB) $28^{\circ} \mathrm{C}$. Dengan perkataan lain suhu/tekanan panas di area stone crusher masih dapat dikatakan aman tetapi sudah perlu diantisipasi karena pada umumnya sudah melebihi $27^{0} \mathrm{C}$.

\section{KESIMPULAN DAN SARAN}

Dari hasil penelitian dapat diambil kesimpulan :

1. Tingkat kebisingan di lokasi kegiatan stone crusher (lokasi operator 97,31dB,lokasi lalu lintasnya pekerja 95,47dB serta lokasi bengkel 89,14dB).

2. Dari hasil pengukuran atau perhitungan suhu di lokasi stone crusher (lokasi operator rata-rata $27,41^{\circ} \mathrm{C}$ dan di bengkel rata-rata $\left.26,80^{\circ} \mathrm{C}\right)$.
3. Berdasarkan KEP51/MENAKER/1999 untuk tingkat kebisingan semua lokasi yang diukur ternyata sudah melenihi Nilai Ambang Batas (NAB), sementara untuk suhu sudah mendekati NAB.

Disarankan untuk meningkatkan kesadaran bagi seluruh karyawan untuk selalu menggunakan alat pelindung diri (APD) seperti ear muff atau ear flug disamping safety shoes, safety helmet, masker, untuk pekerja yang bekerja di lokasi Stone crusher yang mengalami kebisingan yang sudah jauh melebihi nilai ambang batas (NAB) yang diizinkan. Dampak dari kenyataan ini akan menurunkan ambang batas pendengaran pekerja tanpa disadari dan lama-kelamaan akan berdampak menjadi Tulian.

\section{DAFTAR PUSTAKA}

Adams, E.C (1975). Science in Building. Hutckinson and Co. London

Budiono, Sugeng. (1996). Hiperkes dan $K K$. Semarang: Bunga Rampai.

Charles E. Wilson. (1817). Noise Control : Measurement, Analysis and Control of Sound and Vibration, New Jersey Institute of Technology.

Granjean, E. (1985). Fitting the Task to The Man, Ed. 4. A Text Book of Occupational Ergonomic. London. New York. Philadelphia.

Http://Www.Academia.Edu/5361011/Wib awa, Adhitya, dkk. (....). Penentuan Tingkat KebisinganLingkunganMenggunak anAlat Sound LevelMeter di SekitarGedungGrahaWidyaWisud a. Intitut Pertanian Bogor, Bogor. 
KEPMENAKER. No: 51/Men/1999. Tentang Nilai Ambang Batas Kebisingan.

Setyawati, Lientje. (1994). Kelelahan kerja kronis. Kajian Terhadap Perasaan Kelelahan Kerja, Penyusunan Alat Ukur. Serta Hubungannya Dengan Waktu Reaksi dan Produktivitas Kerja. Disertasi. Program Pascasarjana, UGM. Yogyakarta.

Sulakmono. (1991). Bahaya Kebisingan dan Cara Pengendaliannya. Public Health F.K. Unair Surabaya.

Suma'mur. PK. (1994). Higene Perusahaan dan Kesehatan Kerja. Jakarta: Gunung Agung.

Thomy, Arfandi. (2006). Hubungan Kebisingan dan Suhu Lingkungan dengan Kelelahan Pada Pekerja PT. PLN (Persero). Jambi

Tarwaka. (2004). Ergonomi untuk Keselamatan, Kesehatan Kerja dan Produktivitas. Surakarta: Unisba Press.

Yanti. (2009). Hubungan Tekanan Panas, Kebisingan, Giliran Kerja Dengan Perasaan Lelah Pada Pekerja Di Bagian Produksi Di PT. Batang Hari Tembesi. Jambi 